REFLECTIONS:

NEUROLOGY AND THE

HUMANITIES

Section Editor

Michael H. Brooke, MD

\section{Teaching rounds and change}

Steven P. Ringel, MD

Address correspondence and reprint requests to Dr. Steven P. Ringel, University of Colorado Denver, 12631 E. 17th Avenue (B-185), Aurora, CO 80045 steven.ringel@ucdenver.edu
Some things change and other things stay the same. As I was filling out evaluations for two young trainees I had just worked with, it dawned on me that residents never seem to age, and their eagerness to learn is a constant. My mind kept drifting back to the patients we had seen together. So much has changed in the way we deliver health care over the four decades since I began my medical education. The topics I discuss on rounds these days have changed as well.

Every year I seem to focus more on the ambiguity of disease and human behavior and less on the explosion of medical discovery I emphasized earlier in my career. Why? Because experience has taught me that there is a lot that residents and students need to understand in caring for patients that they cannot find in textbooks.

I remember when Jeffrey, a new neurology resident, presented the story of Michael Jones on rounds. He was eager to expand on the differential diagnosis of this aging man's degenerative basal ganglia disorder. Mr. Jones had undergone countless tests in our movement disorder clinic, but his precise diagnosis remained unclear. Jeffrey had completed a quick literature search in a matter of minutes with a few key strokes of a computer. Of course, we spent time reviewing the conditions Jeffrey indicated could lead to this man's severe disability. But since there are voluminous textbook details readily available to residents, I did not have to belabor that conversation.

My resident's computer search failed, however, to include any practical discussion of the increasing confusion that led to Mr. Jones' admission. He was too bewildered to verify the host of medications the clinic notes reported that he was taking; his wife was uncertain as well. She had reported that neither she nor her husband were very clear about his condition. "The doctors use words we don't always understand. Michael takes so many pills and he's getting increasingly depressed because he can't get around anymore."

What should I talk about now? I could remind the residents that numerous studies confirm that patients with chronic conditions take the dose of medi- cations we prescribe about half the time and compliance drops dramatically after 6 months. The consequences are enormous since up to two-thirds of medication-related hospital admissions are due to poor medication adherence-both overdosing and underdosing. Had we not admitted several patients with known seizure disorders these last weeks in whom we suspected their most recent seizures resulted from not taking prescribed medications? Why do patients fail to take their medications? Is it lack of information, side effects, forgetfulness, emotional factors, cost, or perhaps several reasons? And how can we keep it from happening again?

Should I remind them that nearly half of US adults have trouble interpreting medical information? Not understanding their own condition is medically counterproductive since we know that informed patients are more likely to participate in their care, make wiser decisions, and adhere more fully to treatment recommendations. Yet fewer than 10\% of doctors spend sufficient time thoroughly educating their patients during an encounter. Were we seeing Mr. Jones in the hospital because busy movement disorder specialists had difficulty carving out enough time to explain their medical conclusions and recommendations? How can I get across to them that if they want their patients to participate more actively in treatment, they need to build greater understanding? What words can I use to illustrate that the medical specialization and scientific breakthroughs they have learned can inadvertently cause them to drift further away from their patients' life problems? How will I convey to residents who spend vast amounts of time acquiring technical knowledge that they need to resist feeling more responsible for an organ system than for a whole human being? The pharmacologic treatment of seizures and movement disorders will not solve the problems of a depressed person with a ruptured family and financial worries.

As I moved on to Lynette's review, I remembered a patient she described to me on morning rounds. Gloria Friedman had come to the emergency department (ED) following the sudden onset of numbness 
of her left side associated with a headache. The ED had alerted the stroke team and had begun the steps needed for acute thrombolytic therapy. This month was Lynette's first neurology rotation. She read notes prepared by the on call resident, who had actually cared for Mrs. Friedman in the ED. That resident was post call and now home in bed. His sign out note read "the brain CT was normal; the patient received IV r-tPA; and her numbness resolved.”

Lynette had seen Mrs. Friedman briefly when she came on duty that morning. She was rushing to see her patients before going to a required Managing Emergent Neurologic Conditions conference our faculty had designed for new neurology residents. Fortuitously, the lecture that morning was on the management of acute stroke, and Lynette was eager to demonstrate what she had learned. She listed the management guidelines used nationally by stroke centers and confirmed that she had ordered "everything," including a brain MRI, carotid ultrasound, echocardiogram, barium swallow, and comprehensive clotting studies.

When I interviewed Mrs. Friedman, she was most concerned with her persisting headache and nausea. She had a history of "sick" headaches, but this episode was the first time she had experienced numbness on one side of her body. Since her father had been quite incapacitated from a stroke, she was worried about a similar devastating outcome.

Could it be that the patient had experienced a migraine headache and that the admitting resident had jumped the gun in administering thrombolytic therapy? I told the residents that when I first began to practice neurology, I was eager to treat everyone aggressively. "Stroke alert" not withstanding, experience has taught me the wisdom of the dictum primum non nocere. If we are not confident that we can help someone, we would do well to be certain that we do not make matters worse. Fortunately, we had not hurt this patient, and we certainly could offer her relief of her headache.

What about the tests that Lynette had ordered after hearing the emergency stroke management presentation? At a time of runaway health care costs, is it cost-effective to order tests that are unlikely to yield useful information? Physician and patient adherence to evidence-based guidelines has been shown to improve many patient health outcomes so a more standardized approach to care certainly has merit. The development of rules-based behavior for groups of patients is valuable in creating greater certainty for physicians and patients. But, in this instance, if our patient had a migraine rather than a TIA, the protocol had little value. I wanted the residents to understand that uncertainty is part of medical decision-making. Rules can devalue the very clinical judgment that is funda- mental for the care of individual patients. The scientific knowledge and evidence that we acquire can inform but never replace our clinical judgment which is fundamental to patient care.

Although off duty, I reminded myself to gently offer the admitting resident my analysis of Mrs. Friedman's diagnosis and management. Because of mandated work hour limitations, it is increasingly common to hear reports second-hand from crosscovering residents when the admitting resident is off duty. Gone are the days when being a house officer is a rite of passage and fatigue a badge of success. Today's training guidelines require us to place a higher value on education and patient safety than on meeting hospital service demands. But the constant way patient responsibility is handed off can lead to miscommunication. And since patients are admitted and discharged as quickly as possible these days, everyone scurries to get tests ordered and treatments completed. While we know that haste often makes waste, worse yet, it can lead to errors. To avoid mistakes, surgeons are now required to take a time out in the operating room to make sure that everything is right before beginning the procedure. Despite today's pressure to see patients quickly and reduce hospital length of stay, at times we need to slow down to make sure we are doing the right thing.

Jeffrey and Lynette both learned how to get to the crux of a situation from managing one of my private patients. James Barkley, a 58-year-old truck driver with amyotrophic lateral sclerosis (ALS) who I had been seeing for 2 years, was admitted for a gastrostomy tube insertion. Jeffrey reported to our team that Mr. Barkley had been losing weight and choking while eating. Because of the marked weakness of his limbs, his wife was feeding him and would now have to learn how to administer tube feedings. She was determined to continue the two dozen herbs, vitamins, and minerals that both of them believe were helping treat his condition. She also expressed concern that at times when she was at work she could not find someone to help her husband. They had very limited income, so paid help was not realistic and their children lived in other parts of the country. Having spent many hours with the two of them, I knew how exhausted both were.

I expected Jeffrey to ask me about the latest research and treatment available for ALS since he knew that I had been involved in numerous ALS treatment trials. Instead, he wanted to know whether we should discourage the Barkleys from taking so many pills that are of unproven benefit. Were they not just expensive placebos? To answer his question, I first turned to studies using modern imaging technology. It is now understood that the placebo effect is an actual physiologic phenomenon. Beliefs, such as an- 
ticipating pain relief, lead to changes in neurotransmitter levels in selective areas of the brain. In fact, studies show that expectation is the most powerful predictor of who will benefit from a treatment. I then added a personal note: were we being open-minded and helpful if we dismissed these seemingly harmless approaches and took away all hope of benefit?

We spent considerable time talking about the many roadblocks the Barkleys were facing. Our training has traditionally emphasized the management of acute disease. But the complexity of patients' problems has grown exponentially over my career: people live longer and have multiple maladies, medical costs are increasingly burdensome, and families scattered around the world struggle to provide assistance for chronically ill or disabled loved ones. Clinical judgment and decision-making have to take all these factors into consideration.

As I completed Lynette's evaluation, I remember that she asked how much I told patients with ALS on a first visit about this progressively fatal, paralytic illness. I could not provide an easy answer because each patient is unique. Learning how to break the news and how to provide information that fits with each person's unique identity is a skill acquired over a lifetime. As teachers, we can only begin to guide our students in developing these skills.

So in looking into a mirror of my own career, it is not just my physical appearance that has changed over the years; my approach to teaching has evolved as well. During my neurology residency, my educational opportunities were almost exclusively directed toward the body of knowledge of neurologic disorders. We infrequently considered the complex medical, legal, financial, and ethical issues that arise in caring for patients. It is not easy to master these added dimensions of medical care that matter as much as clinical findings, but I am committed to teaching residents that our patients deserve no less. 


\section{Neurology}

Teaching rounds and change

Steven P. Ringel

Neurology 2009;72;2049-2051

DOI 10.1212/WNL.0b013e3181a92c01

This information is current as of June 8, 2009

\section{Updated Information \& Services}

Citations

Subspecialty Collections

Permissions \& Licensing

Reprints including high resolution figures, can be found at: http://n.neurology.org/content/72/23/2049.full

This article has been cited by 1 HighWire-hosted articles: http://n.neurology.org/content/72/23/2049.full\#\#otherarticles

This article, along with others on similar topics, appears in the following collection(s):

All Clinical Neurology

http://n.neurology.org/cgi/collection/all_clinical_neurology All Education

http://n.neurology.org/cgi/collection/all_education

Methods of education

http://n.neurology.org/cgi/collection/methods_of_education

Information about reproducing this article in parts (figures,tables) or in its entirety can be found online at:

http://www.neurology.org/about/about_the_journal\#permissions

Information about ordering reprints can be found online:

http://n.neurology.org/subscribers/advertise

Neurology ${ }^{\circledR}$ is the official journal of the American Academy of Neurology. Published continuously since 1951, it is now a weekly with 48 issues per year. Copyright. All rights reserved. Print ISSN: 0028-3878. Online ISSN: 1526-632X.

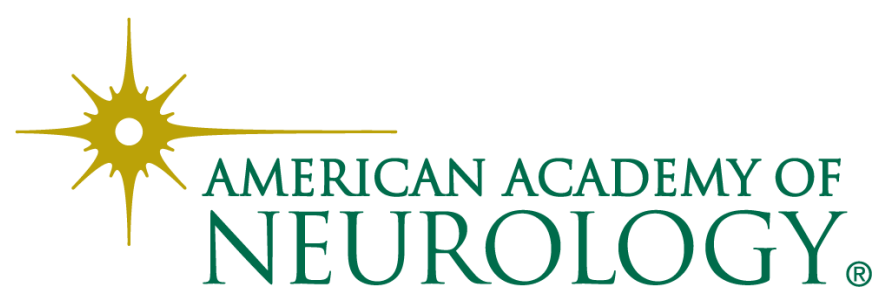

